\title{
LA ENFERMEDAD COMO MEDIUM. APROXIMACIÓN A LOS DIBUJOS DE UNICA ZÜRN
}

Luis Puelles Romero

Universidad de Málaga

Data recepción: 2018/12/04

Data aceptación: 2019/06/10

Contacto autor: Ipr@uma.es

ORCID: https://orcid.org/0000-0002-9541-7073

\section{RESUMEN}

Situándonos en un campo de intersecciones conformado por el surrealismo, el informalismo y el outsider art, se elabora en lo que sigue una propuesta hermenéutica atenta a la complejidad -empezando por su estatuto como "objeto artístico"- de la obra dibujada de Unica Zürn. La coincidencia, a partir de los años cincuenta, entre la realización de sus inquietantes dibujos y sus continuados internamientos en sanatorios mentales hace difícil eludir la consideración de cómo inciden en sus trabajos la esquizofrenia que se le diagnostica. A partir de estas consideraciones, en la segunda parte de este artículo se acude a la fenomenología, en particular a las propuestas hechas en esos mismos años por su amigo Gaston Bachelard, y a la formulación de lo figural por parte de Jean-François Lyotard, procurando reunir ciertas herramientas de interpretación que mantengan la singularidad de estas imágenes en términos de irreductibilidad a las tentaciones que quisieran tomarlas en clave patológica.

Palabras clave: Zürn, automatismo, outsider art, enfermedad, fenomenología

\section{ABSTRACT}

In looking at a field where surrealism, informalism and outsider art all intersect, we offer a hermeneutic proposal dealing with the complexity of the drawn work of Unica Zürn, starting with its status as an "artistic object". The fact that the creation of her disturbing drawings coincided with her continued confinement in psychiatric hospitals from the 1950s onwards makes it hard to avoid assessing how the schizophrenia she was diagnosed with impacted on his work. Moving on from these considerations, in the second part of this article we turn to phenomenology, in particular to the proposals made during those years by her friend Gaston Bachelard, and to the formulation of the figural by Jean-François Lyotard, by attempting to bring together interpretative tools that maintain the singularity of these images in terms of an irreducibility to the temptations that sought to interpret them in a pathological manner.

Keywords: Zürn, automatism, outsider art, disease, phenomenology

La psiquiatría ha estudiado el enorme campo de las aberraciones, de las vesanias, de los accidentes pasajeros que revisten de una penumbra a las almas más claras. Reciprocamente, ha descubierto en los espiritus más turbados sintesis que aún son pensamientos suficientemente coherentes para dirigir una vida y para crear una obra. Gaston Bachelard, Lautréamont (1939)

Hay seres destinados a ser adorados, y otros a adorar. Yo he pertenecido siempre a los segundos. Asombrarme, admirar, adorar-incansablemente-. 
Permanecer en la sombra, mirar, observar, es mi manera pasiva de vivir. Unica Zürn, "Notas de una anémica" (1957)

Conducidos por la intención de adentrarnos en la complejidad del imaginario creado -escrito y pintado- por Unica Zürn, quisiera comenzar estas líneas asignándole un atributo que habrá de ayudarnos en nuestra determinación. Es el de marginal. Si nos detenemos en la significación de este adjetivo, al menos dos campos de definición se nos ofrecen: el primero nos diría de Zürn que es una artista -ya veremos su estatuto, también problemático, como artista o autora- poco conocida y reconocida, apenas "institucionalizada", posiblemente eclipsada por la relevancia que sí tuvo y tiene su compañero Hans Bellmer ${ }^{1}$. Pero hay otra posibilidad de consideración de su marginalidad: la que, más allá de la "categoría" que las disciplinas, las instituciones o el mercado puedan llegar a otorgarle, nos advierte acerca de una posición que no dependería de eventuales factores externos, sino de una identidad más tangencial que central, más definida por intersecciones que por núcleos puros. En tal caso, podría estimarse que la obra de Unica Zürn posee una marginalidad constitutiva, independiente de los mayores o menores méritos que se le pudieran conceder; una marginalidad que acaso podría ser acogida bajo la fórmula de outsider art, acuñada por Roger Cardinal en 1972 (algo después y casi como corolario de unas décadas en las que el art brut y, en general, las expresiones de los "locos" y los naifs son reivindicados por los estudios de Hans Prinzhorn y los surrealistas)2.

Dejemos esta primera cuestión, la de una especie de marginalidad "intrínseca", apenas sugerida, tomándola como consideración preliminar, para ir a la segunda. Cuando afirmamos que el corpus legado por Unica Zürn se caracteriza por su "lateralidad", también decimos que sus trabajos son confusos, ambiguos, de difícil circunscripción artística. Y esta confusión nos pone ante un asunto que no puede eludirse cuando se persigue penetrar en la significación artística de las imágenes que a ella debemos, y que no es otro que el de la autoría. Si bien los escritos de Unica Zürn mantienen una lucidez innegable, tanto en la coherencia de sus contenidos como en el uso de la gramática, los dibujos realizados desde los años cincuenta, ya conviviendo con Bellmer en París, se sitúan en un espacio ambiguo, prestándose, por una parte, a ser tomados como "meros" documentos testimoniales de angustiosos estados de enajenación mental y, por otra, a ser comprendidos como muestras de una subjetividad capaz de intención y conciencia.

Así, la interpretación que hagamos de las imágenes dibujadas por Zürn no se libra con facilidad de esta oscilación entre el postulado de intencionalidad y responsabilidad sobre lo creado, lo que haría de ella una autora, y la suposición de que estos trazos realizados durante sus internamientos psiquiátricos sólo son síntomas de su esquizofrenia. Y probablemente esta disyunción no sea más que una aporía: justamente una tensión irresoluble que nos sitúa en una cierta menesterosidad hermenéutica. Es precisamente Roger Cardinal quien, refiriéndose a los dibujos de Zürn, fija ambos términos de interpretación: "Dibujos compuestos en el trance, y así en un estado de inconsciencia; o bien en un estado segundo que no impide una parte de lucidez, esto es, de juicio y control" ${ }^{\prime 3}$. ¿Cómo dilucidar la posición conveniente? ¿Hasta dónde lo intencional y a partir de dónde lo involuntario? Algo más abajo, Cardinal busca algún asidero detectando las posibles analogías de este imaginario recurriendo a fuentes concretas de la historia del arte, pero también buscando la analogía con otros universos menos deliberativos:

Casi alucinante, la obra de Zürn muestra semialusiones involuntarias que el conocedor del arte del dibujo se apresurará a agarrar. Las múltiples riquezas estimulan las comparaciones: he ahi una referencia a Wols, a Michaux, a Jean Arp, a Bellmer; he ahi un pequeño eco de Masson o de Picasso (los dibujos del Minotauro), cuando no de Ursula, de Anne Grgich, de Ody Saban. Estas cabezas combinadas nos devuelven a Arcimboldo, si no a Dalí. Algunos dibujos estremecidos y nocturnos tienen cierta afinidad con los dibujos espiritistas de Victor Hugo. Aquí y allá, yo encuentro parecidos con el estilo de dibujantes esquizofrénicos como Edmund Monsiel o August Klett, de la colección Prinzhorn, o incluso Nadja (el dibujo al que André Breton llama "un verdadero escudo de Aquiles"). La tendencia a la proliferación en artistas-médiums tales como Raphaël Lonné ofrece también un paralelo. Pero 
toda analogía sólo es útil para agudizar nuestro sentido de la diferencia. Como indica su nombre, la aportación fundamental de Zürn es única4.

Estas líneas, que podríamos tomar como brújula, nos dan algunas pistas de interés. La primera es que no se diferencia en ellas con nitidez a los artistas "naturalizados" por las instituciones y las disciplinas teorizantes de aquellos otros marcados por la enfermedad mental. Más abajo retomaremos las implicaciones que en esta indiferenciación se contienen, cuando tratemos de servirnos de la fenomenología como método de abordaje de estas imágenes.

Otra consideración que podremos aprovechar de las que hace Cardinal es la de tomar al artista como médium. Ya desde el lón platónico, hasta llegar a los escritos primeros de Breton, hay una extensa tradición que comprendería al artista no en su capacidad de voluntad y decisión, sino más bien en su don para prestarse a ser receptor vehicular de otras fuerzas o poderes, esto es, como medio pático a través del cual se produjese algún tipo de revelación. Aún más: alguna revelación al menos inicialmente ajena a la pretensión de conformar una representación de valor estético y, más bien al contrario, inherente a la expresión de una verdad (metafísica o "inconsciente", Ilegada desde alguna instancia absoluta o desde los sustratos profundos del psiquismo).

Se descubriría de este modo una posibilidad de creación -desde luego hasta ahora escasamente atendida- que consistiera en la capacidad del artista para actuar como receptor, como medio de una "fuerza" (a saber cuál) que fuera invocada y conducida a emergencia. Tendremos ocasión de volver sobre este asunto, pero dejemos apuntadas unas palabras de Anouchka D'Anna, pertenecientes a su libro Unica Zürn. L'écriture du vertige:

Enfermedad que ella disfruta cada día, que la internan en un más allá extraño y maravilloso, y que por nada del mundo ella querría abandonar, a pesar del precio que hay que pagar: la depresión y los episodios de recaídas catatónicas. Unica no cree en su curación. Ella no quiera abandonar las bellas sensaciones que le procura su enfermedad, "el estado muy noble de médium", como ella lo llama. No parece que viva su locura como una alienación, sino como una liberación, a pesar del carácter fuertemente angustiante de sus alucinaciones.
Quizá D'Anna exagere las virtudes del estado de enfermedad sufrido por Unica, cuya desolación creció hasta concluir en su suicidio, pero sí vale la pena intentar reconocer el interés que tuviera la valoración de la enfermedad como un factor favorable a la creación, y no como un impedimento o una insuficiencia. Acaso ya desde el romanticismo, y alcanzando al menos a las vanguardias, mantener posiciones demasiado "intencionalistas" en lo relativo a la producción de las obras nos privaría de entender en su creciente complejidad los entresijos de las poéticas irracionalistas en todas sus posibilidades: desde lo azaroso a lo inconsciente y "automático", o la adopción de estados extremos (pensemos, por ejemplo, en el accionismo vienés...).

Queda aún una última reflexión antes de entrar en el universo personal de Unica Zürn. Del mismo modo que nos hemos preguntado por la oscilación que nos lleva desde la alienación sin intención hacia la posibilidad de que quepa reconocer la existencia de umbrales de autoría en estos dibujos, también parece oportuno interesarse por cómo incide en la recepción que se hace de sus trabajos el hecho circunstancial, pero desde luego nada anecdótico, de que Zürn fuese compañera de Hans Bellmer, artista más o menos integrado en el orbe surrealista y con una clara influencia sobre ella. A este respecto, preguntas posibles serían: ¿Si no hubiera sido la compañera de Bellmer durante sus últimos diecisiete años, en los que participó de las actividades y relaciones surrealistas, la tendríamos por artista -más o menos digna de estimación- o habría de quedar relegada a la turbia galería de enfermos mentales capaces de dibujar con cierta continuidad? ¿Qué importancia puede tener para la valoración de sus dibujos saber que esta mujer alemana llegada a París en 1953 entabló amistad con escritores y artistas como Breton, Brauner, Ray, Duchamp, Bachelard, Ernst, Tanning, Fini, Lam, Arp, Perec...? ¿Esta circunstancia podría ser eludida en el recuento de los méritos que podamos reconocerle desde el punto de vista de su "inclusión" en la pomposa Historia del arte?

Presentadas estas primeras consideraciones, convendrá que vayamos acercándonos al universo específico de esta escritora y dibujante. Comencemos dando cuenta de la Unica Zürn 


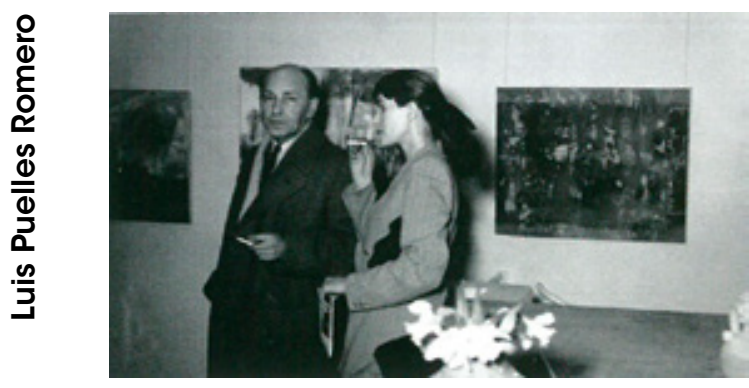

Fig. 1. Hans Bellmer y Unica Zürn, Berlín, 1953

(Grünewald-Berlín, 1916-París, 1970) más conocida, la autora de un corpus de unos ciento treinta relatos, iniciado hacia 1949, y de dos escritos de extensión media y de gran valor literario compuestos en torno a 1965: Der Mann im Jasmin [El hombre jazmín] y Dunkler Frühling [Primavera sombría]. Este segundo lleva un subtítulo elocuente: Eindrücke aus einer Geisteskranken [Impresiones de una enferma mental] ${ }^{6}$.

A estos trabajos hay que añadir los anagramas practicados por Zürn, unos 100 en total (los primeros fueron publicados en 1954, en Hexentexte (Textes sorcières), donde se presentan diez dibujos y seis anagramas) ${ }^{7}$. Además, la editorial Joëlle Losfeld publicó en 2000 el conjunto de textos titulado Vacances à Maison Blanche. Derniers écrits et autres inédits. Salvo el primero de ellos, "Notas de una anémica" (de 1957-1958), todos los demás fueron escritos en el último año de su vida, entre 1969 y 1970, y conservan un cierto estado de lucidez.

No serán sus escritos los que nos ocupen en lo que sigue, sino sus turbadores dibujos. Para llegar a ellos, me parece que es preciso situarse en una fecha de arranque: el mes de septiembre de 1953. Es entonces cuando Unica Zürn y Hans Bellmer se conocen en Berlín (fig. 1). En ese momento ella malvive publicando cuentos perversamente infantiles en periódicos alemanes y suizos. Tiene 37 años y es madre de dos hijos (fig. 2). En los meses anteriores a este encuentro, mantuvo una relación con el pintor Alexander Camaro, quien la inicia en la acuarela y en el medio artístico berlinés.

Vale la pena leer la rememoración, en tercera persona, que ella misma hace de aquel primer encuentro con Bellmer:

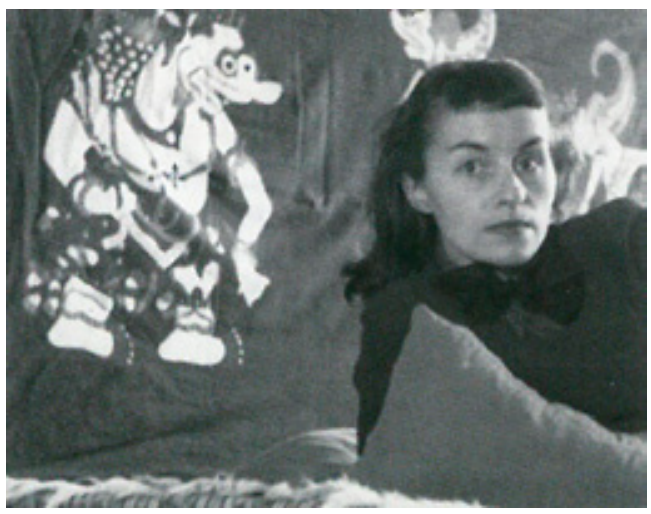

Fig. 2. Unica Zürn en Berlín, 1953

En Berlín, en la época en la que ella pasa hambre, ella comienza a pintar por primera vez, trabajando con frenesí en sus cuentos, que los periódicos les compran por casi nada. El amigo pintor, Alexander Camaro [...], le ha regalado una caja de colores y unos cuadernos para dibujar. Ella moja el papel con una esponja y, con un pincel grueso, lo impregna de colores que, al diluirse, toman bellas formas vegetales [...]. Sus primeras producciones son imágenes garabateadas que suscitan los gritos de espanto cómico de su amigo marchante de arte Rudolf Springer ${ }^{8}$.

Y será justamente a través de Springer como ambos lleguen a conocerse. Démonos el placer de conocer los detalles de cómo ocurrió leyendo a la propia Unica:

Restablecida, ella acude a una inauguración de su amiga Anneliese Kuhk, organizada en un restaurante francés del Kurfürstendamm. Desde hace unos días, ella está obsesionada con un rostro particular. $Y$ de pronto se encuentra frente a un rostro que presenta un enorme parecido con esta obsesión imaginaria: el rostro de Bellmer. Él está en una mesa con Springer y quiere saber quién es ella. Springer los presenta y los invita a su casa de campo el siguiente domingo?.

"Ella lo ama desde el primer instante" ${ }^{10}$. Bellmer ha viajado a Berlín por primera vez desde que se instalara en París en 1938. Rudolf Springer le había organizado una exposición en la librería de la Maison de France. Sin embargo, en este punto los recuerdos divergen: Bellmer declararía que ambos se conocieron en la inauguración de esta misma exposición. Webb nos traslada unas palabras del 


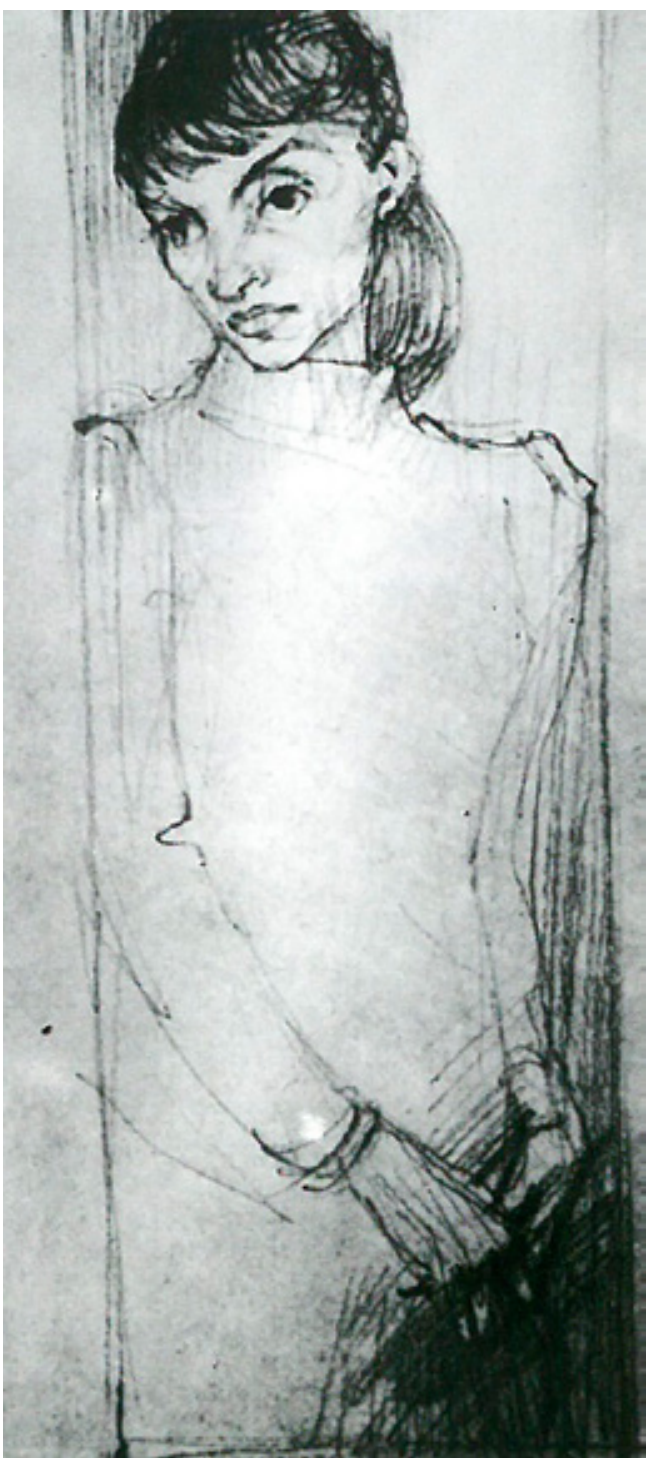

Fig. 3. Hans Bellmer, Retrato de Unica, 1954

artista que hoy pudieran parecernos algo inquietantes: "[...] vestida de negro y con una rosa roja en el ojal, con su rostro inexpresivo, Unica se parecía increíblemente a la muñeca"11 (fig. 3). De un modo u otro, lo cierto es que en noviembre de ese mismo año vuelven juntos a París y se instalan en la rue Mouffetard, donde vivirán doce años (fig. 4).

Detengamos aquí nuestros comentarios biográficos para reparar en una especie de enclave.

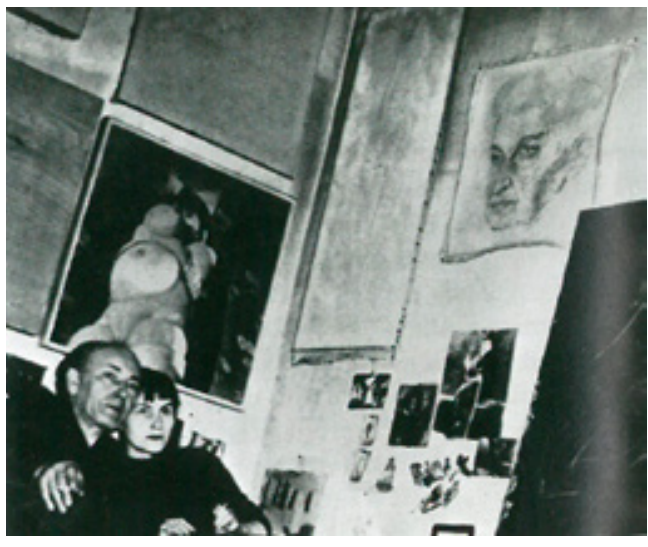

Fig. 4. Hans Bellmer y Unica Zürn, rue Mouffetard, París, 1958

Estamos en los años cincuenta, ahora en París. Y, a partir de aquí, recuperemos aquella condición de marginalidad o carácter tangencial que asignábamos a los dibujos de Zürn para proponer una especie de campo de intersecciones entre el surrealismo (a), el informalismo (b) y el art brut y outsider (c); tres campos que se cruzan en París entre los años cincuenta y setenta. Estas intersecciones nos darán alguna explicación de la indefinición de los trabajos de Zürn.

(a) Unos años después de instalarse en París, Unica tendrá dos exposiciones en la galería Le Soleil dans la Tête, en mayo de 1956 y en octubre de 1957. Ambas contarán con un Prefacio de André Pieyre de Mandiargues, gran amigo de la pareja. A la primera acuden personajes como Jean Wahl y Gaston Bachelard, Breton, Brauner y Man Ray. Esto nos va dando claves para entender cuál es el capital simbólico que recibe Unica de su relación con Bellmer.

En 1957, durante un viaje a Berlín, sufre un aborto y padece su primera depresión nerviosa, debiendo ser ingresada en la clínica Wittenau. Continúa publicando anagramas en diversas revistas. A partir de esta crisis su estado irá empeorando hasta revelarse una esquizofrenia.

Hacia final de ese mismo año, ambos participan en la Exposition surréaliste internationale, organizada por Breton y Duchamp en la galería Daniel Cordier de Paris -rue Mironesnil-, dedicada a EROS. En 1960 vuelve a ser hospitalizada en Berlín, donde intenta suicidarse; vuelve a Paris en 
1961 en silla de ruedas. En septiembre es ingresada, por casi dos años, en Sainte-Anne. Henri Michaux la visita a menudo y le lleva materiales para que dibuje.

D'Anna resume bien su relación con los surrealistas:

La relación de Unica con Bellmer implica su encuentro determinante con el surrealismo. Simbiosis perfecta: Unica encuentra su verdadera familia de acogida. Ellos son los primeros en reconocerla, en darle apoyo psicológico, amistoso, ayuda económica, y le muestran su interés. Gracias a ellos Unica se siente comprendida y arropada. Ella aprende mucho de su contacto con ellos, los observa en la sombra con un ojo admirativo y fascinado. Sin embargo, para la mayoría de ellos no es más que "la mujer de Hans Bellmer"12.

Vayamos a las entrañas del surrealismo para tomar algunas pistas que nos aproximen a la complejidad de los dibujos de Zürn, en particular cuanto el grupo bretoniano aportó en relación con el automatismo. La primera gran fuente relativa al hallazgo de la "escritura automatista" la toma Breton del psiquiatra Pierre Janet, autor de L'Automatisme psychologique, muy leído en Francia desde su publicación en 1889. Pero, más allá de este apunte arqueológico, es ya en la definición que del surrealismo se da en el Primer manifiesto (1924), y a partir de la experiencia con Philippe Soupault, con quien escribe en 1919 Les champs magnetiques, donde nos encontramos con unos mimbres que habrán de interesarnos en nuestro propósito: en esa definición -expuesta como si se tomara de un diccionario-, se dice que el surrealismo "se propone expresar, sea verbalmente, por escrito, o de cualquier otra manera, el funcionamiento real del pensamiento"; y sigue Breton diciendo que se persigue la ausencia de todo control racional, situándose la práctica automatista ajena a "toda preocupación estética o moral" 13 .

De esta definición canónica, desearía retener dos elementos de interés hermenéutico para nuestra tarea: uno es que, no sólo mediante procedimientos lingüísticos sino también "de cualquier otra manera" habría surrealismo donde, sin mediaciones, se produjese el funcionamiento inmediato del pensamiento. A pesar de la extrañeza que pueda suscitarnos que Breton elija esta palabra, de difícil comprensión "irracionalista", la de pensée, lo que creo que debe importarnos es el componente procesual y libre de premeditación que el automatismo posee. Se nos descubre así una atención hacia cómo se comportan las funciones cognoscitivas. Una actividad que, a fin de cuentas, genera una revelación. Creo que, sin salirnos de la primera definición de surrealismo, la del Primer Manifiesto (1924), ya encontramos claves fecundas para aproximarnos a los dibujos de Zürn.

El segundo elemento que conservaremos es que esta liberación del pensamiento es ajena a toda persecución estética. Se nos evidencia de este modo la supuesta indiferencia que el surrealismo presta a cualquier objetivo "esteticista". No se trata, por tanto, de aspirar a la representación dotada de cualidades estéticas, sino de dar emergencia concreta a las pulsiones de lo inconsciente ${ }^{14}$. Poco después, en el Second manifeste $d u$ surréalisme, de 1930, puede leerse sobre esto mismo: "Estos productos de la actividad psíquica, tan apartados como sea posible de la voluntad de significar, tan alejados como sea posible de las ideas de responsabilidad siempre prestas a servir como frenos, tan independientes como sea posible de todo lo que no sea la vida pasiva de la inteligencia" ${ }^{15}$. Se hace difícil no reconocer la idoneidad de aplicar a los dibujos de Unica Zürn estas mismas palabras: son revelaciones de "la vida pasiva de la inteligencia". Pero sobre todo lo que aquí importa es la renuncia explícita a la voluntad de significar que se implica en el automatismo surrealista. Esto aporta a las producciones pertenecientes a esta poética un valor de inaccesibilidad que también se encuentra en los extraños dibujos de nuestra berlinesa.

Por su parte, ya Max Morise, en "Les Yeux enchantés", publicado en 1924, en el primer número de La Révolution surréaliste (acompañado significativamente de un dibujo de André Masson), defiende la extensión del automatismo al campo de la creación visual, aunque será en "Des tendances les plus récentes de la peinture surréaliste" (mayo 1939) donde Breton anuncie el advenimiento del "automatismo absoluto" en las prácticas pictóricas del grupo. Poco después, en 1941, Breton publicará Genèse et perspective artistique du surréalisme (escrito durante su exilio 
neoyorquino), un texto fundamental para la comprensión del automatismo en pintura y que tendrá gran influencia en la joven escuela americana (Baziotes, Pollock o Motherwell, quien utiliza para sí la expresión de "surrealismo abstracto").

A la vez que avanzamos a lo largo de estos años de maduración del surrealismo, hasta llegar a la mitad del siglo, observamos un aspecto para nosotros destacable, y es que se transita desde un automatismo surrealista, de revelación de lo inconsciente, de emergencia o revelación de lo reprimido, y en todo caso de pregnancia inicialmente verbal o lingüística, hacia una segunda acepción de automatismo que nos sitúa en los inicios del expresionismo americano y del informalismo europeo, este más gestual y físico. A este respecto, es significativo que el propio Breton amplíe su nómina de pintores afines al surrealismo en las sucesivas actualizaciones que Le Surréalisme et la Peinture tendrá entre 1928 y 1965 (entre otros Jacques Hérold y Toyen, pero también Simon Hantaï o Degottex). Cuando Zürn se instala en París los escritos de Breton son cada vez más receptivos a prácticas y poéticas aparecidas entre los años cuarenta y cincuenta, en los que la figuración se quiebra hacia cierta "figuralidad" tendente a la abstracción (Grupo Cobra, Informalismo y Tachismo).

Además de algunas claves que estimo fértiles para acceder al conjunto de los dibujos garabateados por Zürn, recibimos de este escueto recorrido por la doctrina promovida por Breton la constatación de una apertura creciente hacia la dimensión visualista de la práctica automatista, que le hará acoger en este sentido a André Masson, y Oscar Domínguez, e incluso al propio Max Ernst.

(b) A pesar de esto, se hace inevitable advertir que cuando Zürn se instala en rue Mouffetard con su amado Hans, en 1953, compartiendo desde entonces con él el trato asiduo de los principales artistas surrealista, estos habrán cedido el honor de ser la última vanguardia a los pintores informalistas agrupados en torno a Michel Tapié. Creo que es en este enclave donde hay que buscar la fuerza liberatoria que poseen sus dibujos; más cerca de Michaux y Wols, de Bryen y Hantäi que de cualquier pintor surrealista.
En "Notas de una anémica", la autora escribe unas líneas referidas a una fecha, el 27 de diciembre de 1957, que nos pueden servir de pista: "En cinco días, este año llega a su fin. Un año de grandes encuentros. He podido acompañar a Hans Bellmer a todas las sesiones de pose para sus retratos: Man Ray, Gaston Bachelard, Henri Michaux, Matta, Wifredo Lam, Hans Arp, Victor Brauner, Max Ernst" ${ }^{16}$. La amistad con Michaux será fundamental, hasta el punto de que él es "el hombre-jazmín" de su relato de 1965.

Llegados a este punto, querría prestar alguna atención a la escritura de Michaux, para poder compartir la veleidad de mirar los dibujos de Zürn a la vez que nos dejamos tomar por las palabras del poeta. En particular, son unas pocas palabras, tomadas de su libro Emergences-Résurgences (1972), las que me parece que nos podrían servir para afrontar la singularidad de las imágenes creadas por su amiga. Son estas: "Nacido, crecido, instruido en un medio y una cultura únicamente verbal / Pinto para descondicionarme [me déconditionner]" ${ }^{17}$. Podríamos preguntarnos si no es esto lo que motiva el empeño de la artista en la realización de sus dibujos, con la que se permite suspender las determinaciones de su personalidad social y su subjetividad íntima. Como si sus dibujos, también los de Michaux, sirvieran para liberarse de las exigencias de una vida desdichada. En este caso, suponiendo que esta interpretación pudiera tener interés, no quedarían sus dibujos limitados a ser síntomas más o menos escabrosos de una esquizofrénica fuertemente medicada, sino medios de elaboración de la emancipación.

Algo más abajo, sigue Michaux hablándonos de él y sus líneas, pero dejándonos que "miremos" a Zürn a través de su espléndida escritura:

A mí también, un día, tarde, adulto, me vienen ganas de dibujar, de participar en el mundo por las líneas.

Una línea más bien que unas líneas. De este modo comienzo, dejándome llevar por una, por una sola, sin levantar el lápiz de la superficie del papel lo dejo correr, hasta que a fuerza de errar sin detenerse en este espacio reducido acaba por detenerse. Un entrelazamiento se ve entonces, un dibujo como deseoso de entrar en él mismo [...] 


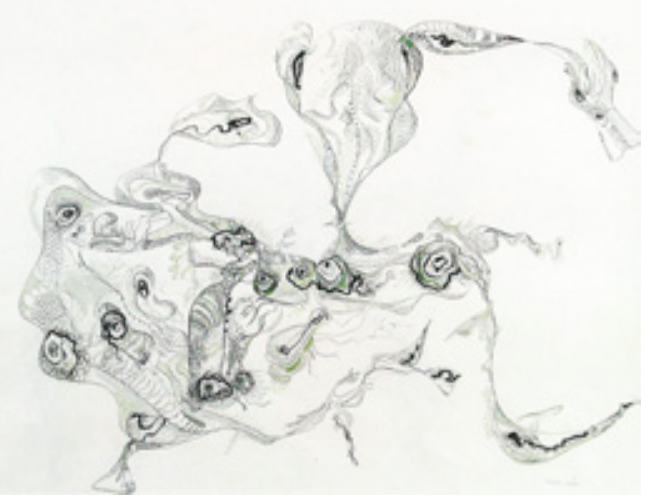

Fig. 5. Unica Zürn, s/t, 1963. Col. Yoko Ono

Como yo, la línea busca sin saber lo que busca, rechaza los hallazgos inmediatos, las soluciones que se ofrecen, las tentaciones primeras. Evitando "llegar", línea de ciega investigación.

Sin conducir a nada, a nada que pueda hacerla bella o interesante, atravesándose ella misma sin tropezar, sin relajarse, sin anudarse, sin apercibir objeto, paisaje, figura.

No chocando con nada, línea sonámbula.

Curva a veces aunque sin abrazar nada.

Sin cercar nada, nunca cercada ${ }^{18}$.

Creo que resulta difícil encontrar un mejor guía para recorrer estos dibujos de Zürn. Líneas que se demoran en su errancia, sin interrumpirse, sin obstruirse en ninguna definición, sin rendirse a ser concreción figurativa (figs. 5 a 7). Pero también sin saber lo que se busca, sustrayéndose de las identidades reconocibles, yendo sin rumbo adonde nunca ha estado y que no sabe qué es ni cuándo llegará. Podría decirse de la propia introspección de Zürn lo que Michaux dice de su línea. Zürn o la mujer-línea.

La última referencia que haremos a este mismo libro de Michaux nos lleva hacia otros territorios, estos compartidos por muchas de las poéticas del siglo XX: el beneficio que supone para la creación el desconocimiento de las técnicas y las destrezas académicas. Así lo dice Michaux: "Mi falta de saber-hacer, mi incapacidad para pintar, preservada hasta edad avanzada, me permite dejarme ir, dejar que todo -sin forzamiento- llegue al desorden, a la discordancia y al desperdicio, la

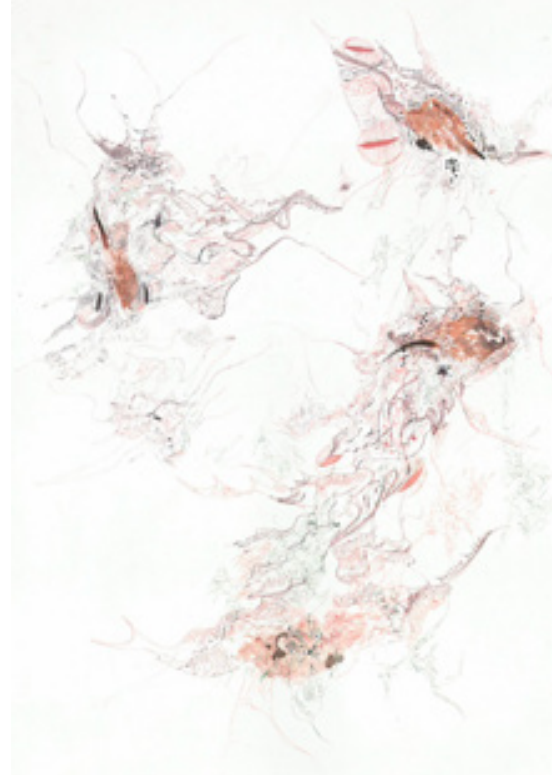

Fig. 6. Unica Zürn, s/t, 1963, tinta china de color y collage con pétalos. Sucesión Zürn

confusión del bien y del mal, sin malicia, sin poder volver atrás, sin rectificación, inocentemente" 19 .

También esto, como es claro, hace de Zürn una artista -si lo es- marginal. Ni siquiera podría decirse que fuese amateur o aficionada. Es otra cosa: sus dibujos son ajenos a toda pretensión de elaboración de algo más o menos apreciable en términos de "obra de arte". Pero, además, lo que dice Michaux es que es justamente esta carencia la que se vuelve ocasión propicia para ganar unas libertades, unas ciertas negligencias que, acaso, el artista bien formado no se permitiera. Zürn no tiene conciencia artística, y precisamente por esto puede alcanzar umbrales expresivos que pudieran ser reprobados desde el punto de vista de su "valor" artístico. Como dice Michaux, su relación con la práctica de dibujar es inocente, ajena a las exigencias de las correcciones o rectificaciones, desprovista de todo criterio de excelencia en el empleo de la técnica o en la conquista de logros formales.

(c) El tercer campo de intersección que habrá de ocuparnos tiene que ver con la dimensión, ya entrevista, que hace de Zürn una enferma mental 
y, así, de sus dibujos unas muestras poco estimables fuera de la rareza testimonial propia de las personalidades alienadas. Para abordar este último ángulo de aproximación parece inevitable reparar en ciertos aspectos de la vida de Unica Zürn, tratando de indagar en cuál es el medio -mental, social, vital- desde el que estos dibujos son realizados (¿o creados?). Esta búsqueda de un punto de vista que nos proporcione alguna ventaja hermenéutica no debe confundirse con un reduccionismo sicologista. Más bien al contrario, se persigue una interpretación a la altura de la complejidad y ambigüedad que dan nacimiento a estos dibujos, los cuales ni se dejan recibir como formas bellas ni tampoco como síntomas de alteraciones mentales más o menos identificables.

Vayamos al triste asunto de los padecimientos de Unica Zürn. Ya en octubre de 1960, mientras pasa una temporada en Berlín, Unica sufre su primer internamiento, en la clínica Karl-BonhöfferHeilstätten, donde habrá de permanecer hasta febrero de 1961. Allí recibe el diagnóstico de esquizofrenia y es fuertemente medicada. Durante estos meses tiene una tentativa de suicidio y realiza sesenta y cuatro dibujos. Vuelve a París el 2 de marzo, en silla de ruedas. Nunca más volverá a Berlín. En septiembre de 1961 ingresa en el Hospital Sainte-Anne, al cuidado del psiquiatra Jean Delay. Michaux le lleva pinceles, tinta y papel.

Aún interna en Sainte-Anne, Zürn expone en enero de 1962 algunos dibujos en la galería Le Point cardinal, con un prefacio de Max Ernst. Su amiga y traductora Ruth Henry relata de este modo esta secuencia de su vida:

Hacía tres años que yo conocía a Unica y, cuando pregunté qué había de nuevo, se me respondió que en ese momento se encontraba interna en SainteAnne; que no era la primera vez que estaba allí, donde cada cierto tiempo recibía un tratamiento a causa de su esquizofrenia, que se manifestaba en crisis irregulares. Se me dijo también que ella había comenzado a dibujar durante una de esas estancias, debido sobre todo a la insistencia de Henri Michaux, que le había proporcionado papel, tinta china y las plumas necesarias ${ }^{20}$.

El 1 de agosto de 1964 Unica es internada en el hospital psiquiátrico La Fond, en La Rochelle, hasta el 15 de septiembre. La pareja piensa en separarse, después de once años en común; ella

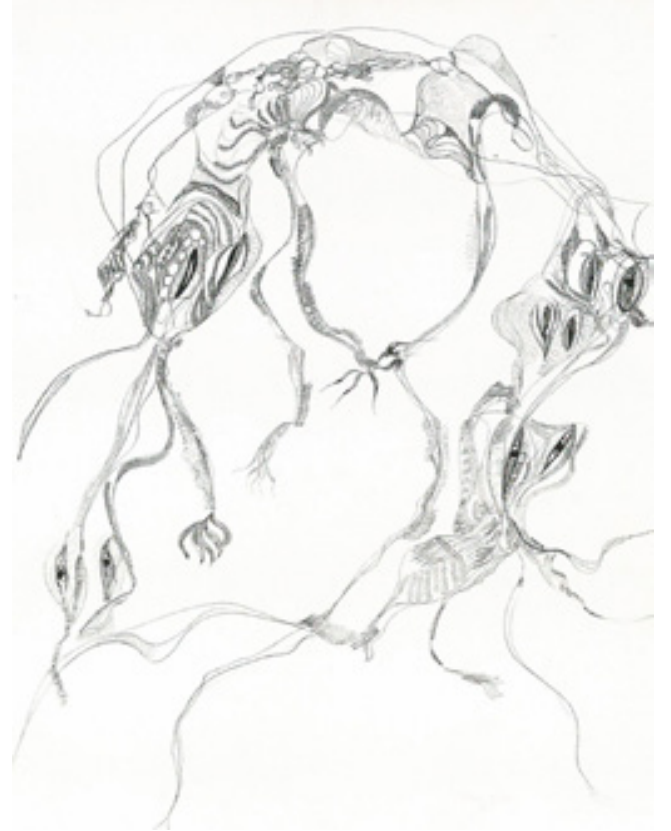

Fig. 7. Unica Zürn, s/t, 1965. Ubu Gallery-Galerie Berinson

vive tres meses en un hotel. Acude a la consulta de Gaston Ferdière, psiquiatra próximo al círculo surrealista.

El 6 de junio de 1966 tiene una nueva crisis de locura y vuelve a ser ingresada, del 15 de junio al 28 de septiembre, en la clínica Maison Blanche, en Neuilly-sur-Marne. Allí reingresa en diciembre de 1969, para permanecer hasta enero de 1970; y tendrá todavía una tercera estancia esta misma clínica, del 4 de abril al 17 de mayo de 1970. Este mismo día es trasladada a la clínica psiquiátrica del Château de la Chesnaie de Chailles. Es ahí donde escribe Vacances à Maison Blanche y Rencontre avec Hans Bellmer. El 18 de octubre de 1970 es autorizada a abandonar la clínica durante unos días. Al día siguiente por la tarde acaba con su vida lanzándose al vacío desde su apartamento.

El tercer ángulo de aproximación a los trabajos de Unica Zürn, quizá más difuso que los anteriores, se interesa por las relaciones entre arte y enfermedad mental en el contexto francés de aquellos mismos años: la cultura del psicoanálisis (Lacan, Ferdiére), el debate psiquiátrico -y antisiquiátrico- en Francia, las implicaciones psico- 


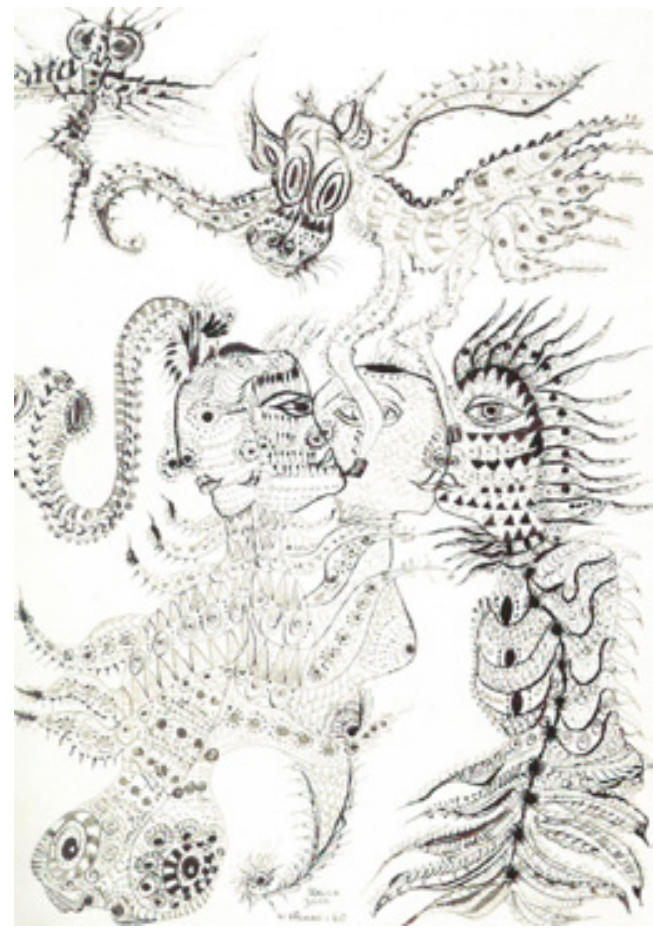

Fig. 8. Unica Zürn, s/t, 1960. Col. Privada

lógicas del existencialismo (podríamos tener en cuenta el "psicoanálisis existencial" del suizo Ludwig Binswanger), pero también las revisiones a las que en estos años se somete la noción de autor por Barthes, Foucault, Deleuze o Derrida, conforman un entramado en el que los dibujos de Unica Zürn encuentran una especie de fermento natural. A estos territorios de exploración convendría agregar la formulación, en 1945, del art brut, por Dubuffet.

Mucho podríamos indagar entre estas puntas, pero me limitaré a traducir unas líneas de Breton, de su L'art des fous, la clé des champs (1948):

No temo avanzar la idea, sólo paradójica a primera vista, de que el arte de aquellos que son incluidos en la categoría de los enfermos mentales constituye una reserva de salud moral. Escapa en efecto a todo lo que tiende a falsear el testimonio que nos ocupa y que es del orden de las influencias exteriores, los cálculos, los éxitos y decepciones existentes en el plano social, etc. Los mecanismos de la creación artística quedan aquí liberados de todo obstáculo. Mediante un perturbador efecto dialéctico, el

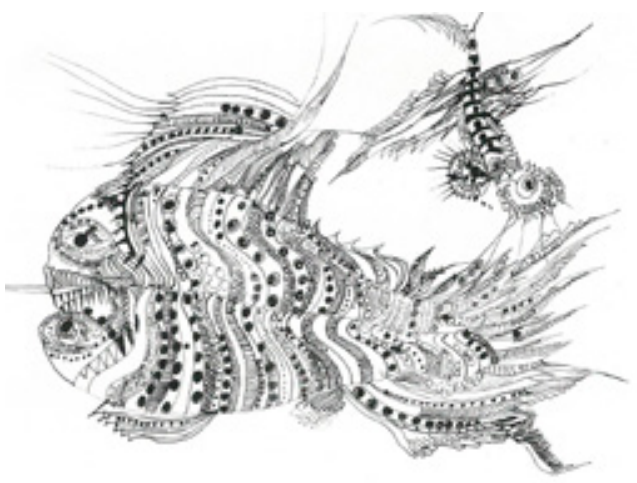

Fig. 9. Unica Zürn, s/t, 1961. Centre Sainte-Anne, París

enclaustramiento, la renuncia a todo provecho y a toda vanidad, a pesar de lo que ellos presentan individualmente de patéticos, son aquí los garantes de la autenticidad total que está ausente en todas partes fuera de aquí [... $]^{21}$.

¿Cómo preguntarnos por estos dibujos realizados entre los años cincuenta y sesenta del siglo pasado? ¿Desde dónde convendrá hacernos con los criterios de recepción para juzgarlos del modo más propicio? ¿Qué "ética hermenéutica" será la más respetuosa con la identidad esquiva de estas imágenes? ¿Debemos conceder prioridad a su estatuto testimonial como síntomas de fuertes alteraciones mentales o, yéndonos al otro lado, su tratamiento preferible es el de tomarlos por objetos estéticos cuyas formas habrían de ser valoradas en términos de gusto? ¿Son "obras de arte" tal y como la Historia del Arte y la Estética, además de la propia práctica museística, implican en esta noción? ¿Es Unica Zürn una "autora" con conciencia suficiente de serlo -y cuánta es suficiente- o una enajenada que dibuja como podría practicar cualquier otra acción prosaica?

En cualquier caso, no es nuestro propósito discernir si Unica Zürn reunía las condiciones para ser llamada con toda contundencia "artista-autora", sino, mirando sus dibujos medio siglo después de su muerte, el de interesarnos por la significación de sus dibujos. Por su consistencia, por su suficiencia para sostenerse solos. Sin quedar relegados a sombras documentales para psiquiatras y siendo al contrario capaces de permanecer poderosos con independencia de cuanto digamos sobre la persona que los creó. Es en ellos donde 


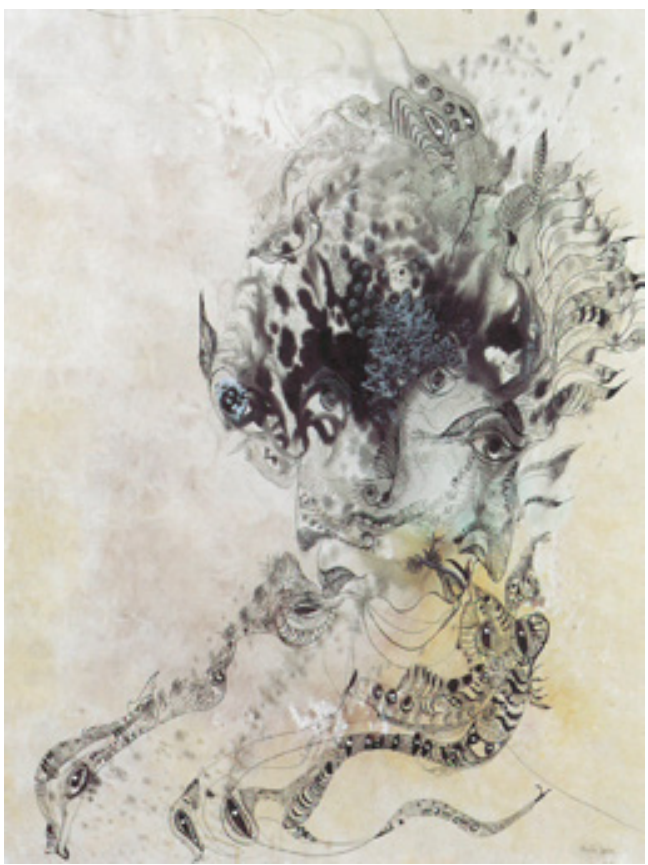

Fig. 10. Unica Zürn, s/t, 1965, tinta china acuarela y aguada blanca. Col. Privada

debemos concentrar nuestra atención, tratarlos como nuestro objeto último de atención. Y, con esta intención, son los útiles aportados por el método fenomenológico los que, según lo entiendo, pueden ser justos con cuanto se muestra en estas imágenes eludiendo las dos tentaciones simplificadoras ya mencionadas: una podría ser la de tomar estas imágenes como "síntomas" o efectos heterónomos, pero hay otro exceso que también convendrá evitar, y es el de la tentación estetizante, esto es, la que supone tomar estos dibujos como expresiones susceptibles de ser tomadas desde la reducción estética y, con ella, más o menos "formalista".

Tomaremos, en primer lugar, la fenomenología de la imagen propuesta por Gaston Bachelard hacia finales de los años cincuenta como instrumento idóneo para adentrarnos en la identidad de estos dibujos de Zürn. También utilizaremos algunas de las claves ofrecidas por Jean-François Lyotard en su importante libro Discours, figure (1971), lo que nos llevará a hacer mención de algún detalle contenido en el ensayo de Deleuze sobre la pintura de Francis Bacon (1981). Este

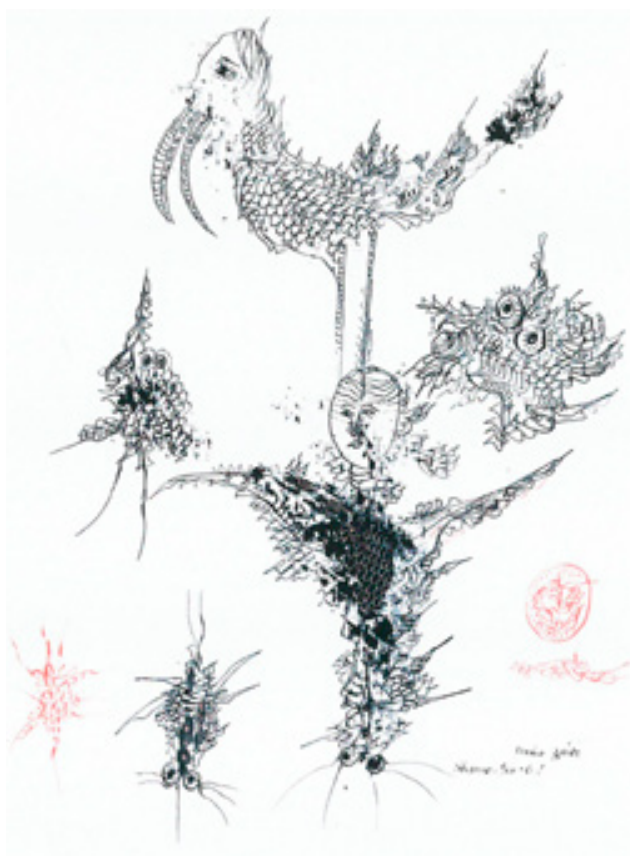

Fig. 11. Unica Zürn, s/t, 1961. Col. Privada

escueto plan de trabajo nos ocupará en las últimas páginas.

Ya en su Lautréamont, escrito en 1939 y anterior a la adhesión -más díscola que obediente- de Bachelard a la escuela fenomenológica, se indaga en "la necesidad de animalizar que se encuentra en el origen de la imaginación. La función primera de la imaginación es crear formas animales" 22 . Es ahí donde leemos: "Las reacciones metamorfoseantes son violentas, porque la creación es una violencia. El sufrimiento padecido no puede ser borrado más que por el sufrimiento proyectado" 23. Creo que este libro de Bachelard, donde se analizan las formas mutantes de la imaginación animalizada, es una espléndida vía de acceso al universo de Unica Zürn, en el que proliferan garras y uñas, escamas, tentáculos, aguijones... Donde pareciese que prima la función sobre la forma reconocible, la acción ofensiva sobre el órgano identificable (figs. 8 a 11).

La poétique de l'espace (1957) es la primera obra de Bachelard de orientación netamente fenomenológica, dedicada a afrontar -a la que da carácter de "problema filosófico"- la pregunta 


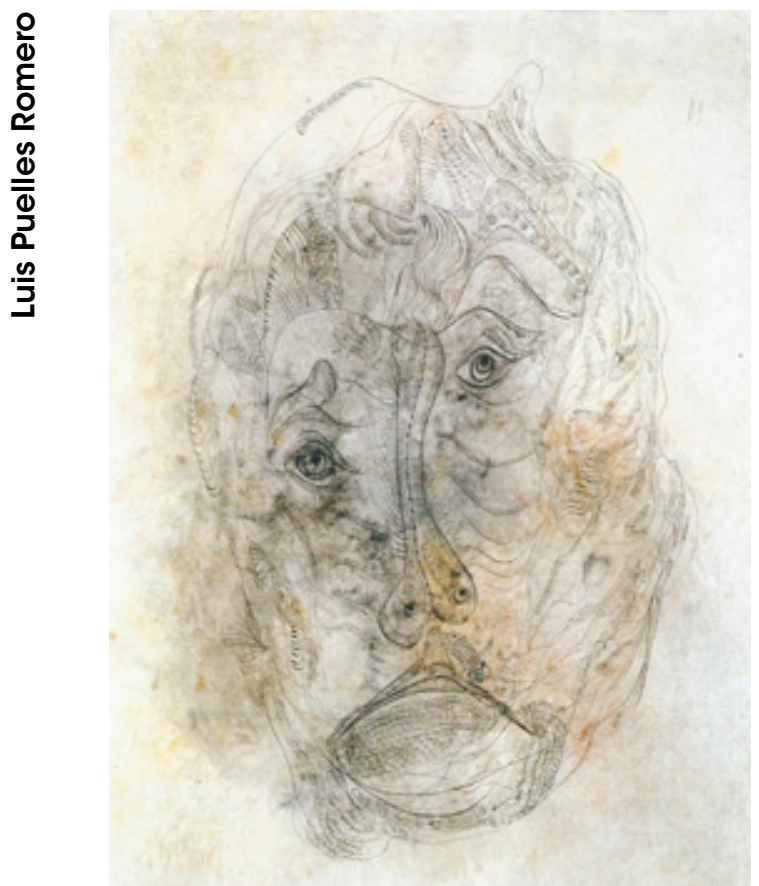

Fig. 12. Unica Zürn, s/t, 1965, tinta china y acuarela. Col. Abcd, París

por cómo debemos acoger "la imagen en sí misma", en su "ser propio", como valor absoluto (es decir, no relativo a otros factores o circunstancias que la desprovean de su propia onticidad). Será el poder de resistencia y de irreductibilidad a la persecución hermenéutica de las causas explicativas el que, desde Kant a Bachelard, se propone como elemento constitutivo del acto creador de la imagen moderna, un acto en tensión liberadora respecto a las posibles explicaciones genealogistas ${ }^{24}$.

El método fenomenológico ofrece a Bachelard esta actitud no reductora: "La exigencia fenomenológica respecto de las imágenes poéticas es simple: ella pone el acento sobre la virtud de origen, tratando de tomarlas en el ser mismo de su originalidad"25. Hay en la intención de Bachelard una voluntad de adhesión a la indeterminación genética de la imagen, una actitud atenta a la aparición o surgimiento de l'image-en-présence. Ni participando de la naturaleza del símbolo ni sirviendo a la significación: la imagen sin determinación (o absoluta). El psicoanalista busca por debajo de la imagen para 'explicar'; apenas pien- sa en ir por encima" 26 . Hay en estas afirmaciones, más centradas en las imágenes poéticas pero que pueden, según creo, trasladarse a los dibujos de Zürn, un cierto procedimiento de respeto a la imagen, consistente en no rebajarla siquiera a explicación más o menos causal. Es, así, la fenomenología de Bachelard, para lo que aquí nos ocupa, un excelente medio de aceptación de la potencia ontogenética que la acción dibujante de Zürn sin duda posee. Bachelard nos educa en la irreductibilidad de las imágenes a ninguna otra instancia de "racionalización" que pudiera entenderlas no en su radical singularidad, sino por cuanto tuvieren de común con otras de su misma condición.

La fenomenología nos enseña que la imagen creada debe ser acogida como una especie de exceso inexplicable. Y es así, "imaginándose", tanto por quien la crea como por quien la recibe, como la imagen posee la potencia de presencia capaz de fertilizar nuestra vida psíquica.

De este modo, la imagen emerge contra la "ley de la gravedad" del significado, con la que quedaría desmantelada y traída a representación: "ella está siempre un poco por encima del lenguaje significante" 27 , escribe Bachelard; ella no es representativa, precisamente porque su identidad coincide con su presencialidad (figs. 12 a 14).

Es momento de acudir a las páginas de Lyotard buscando en ellas posibles intuiciones con las que hacer justicia a las imágenes de Unica Zürn. De Discours, figure tomaremos su concepción de lo figural en enfrentamiento con la tradición de la figuración narrativa:

En cuanto al espacio de la figura, "figural" lo cualifica mejor que "figurativo"; este último término en efecto se opone, en el vocabulario de la pintura y de la crítica contemporánea, a "no-figurativo", o "abstracto"; ahora bien, el trazo pertinente de esta oposición consiste en la analogía del representante y del representado, en la posibilidad ofrecida al espectador de reconocer el segundo en el primero [...] La figuratividad es entonces una propiedad que concierne a la relación del objeto plástico con lo que él representa. Ella desaparece si el cuadro deja de tener la función de representar, si él mismo es objeto $^{28}$ 


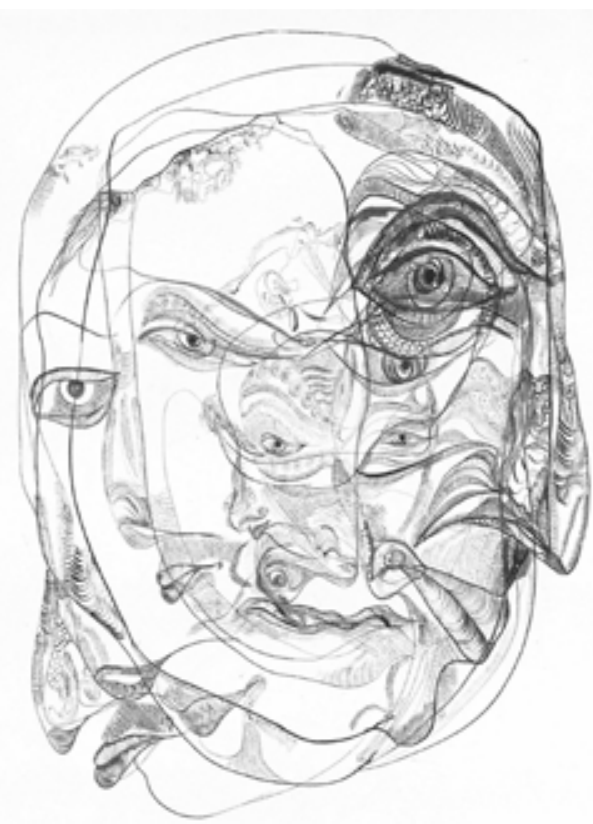

Fig. 13. Unica Zürn, s/t, 1965, tinta china y aguada blanca. Sucesión Zürn

Por su parte, Deleuze, haciendo uso de esta misma categoría hermenéutica aportada por Lyotard y refiriéndose a la pintura de Francis Bacon, aprecia muy bien esta doble vía de resistencia a las codificaciones significantes elaboradas por la figuración:

No solamente el cuadro es una realidad aislada (un hecho), no solamente el triptico tiene tres paneles aislados que ante todo no se deben reunir en un mismo marco, sino que la propia Figura está aislada en el cuadro, por el redondel o por el paralepípedo. ¿Por qué? Bacon lo dice a menudo: para conjurar el carácter figurativo, ilustrativo, narrativo, que la Figura tendría necesariamente si no estuviera aislada. La pintura no tiene ni modelo que representar, ni historia que contar. A partir de ahi ella tiene dos vías posibles para escapar de lo figurativo: hacia la forma pura, por abstracción; o bien hacia lo puramente figural, por extracción o

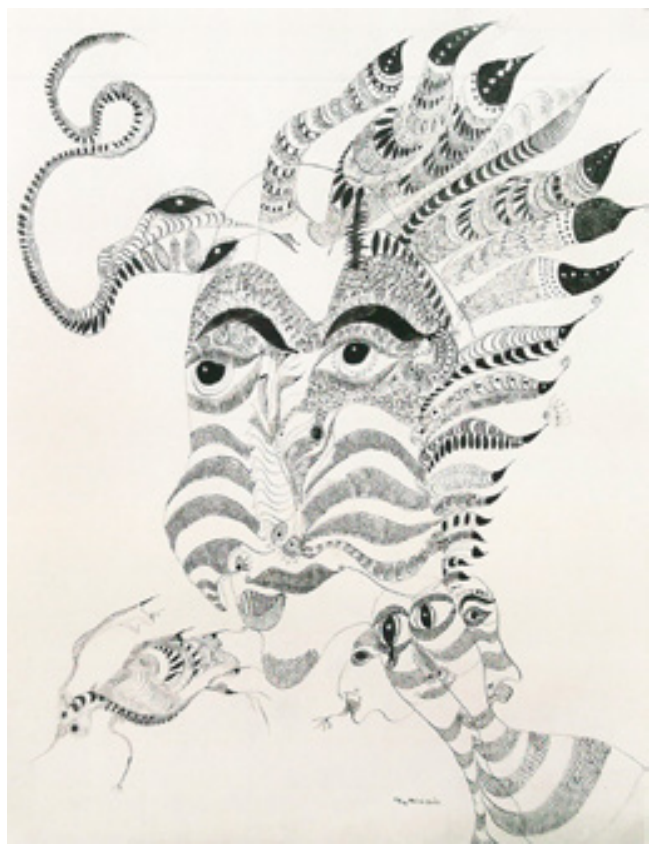

Fig. 14. Unica Zürn, s/t, 1966, tinta china. Col. Amanda Filipacchi

aislamiento. Si el pintor tiende a la Figura, si toma la segunda vía, será, pues, para oponer lo figural a lo figurativo ${ }^{29}$.

Porque, entre estas intersecciones, estas ambiguedades y aporías de las que hemos levantado acta en estas pocas páginas, quedan, en el centro de los ángulos formados, respectivamente, por el automatismo psíquico de los surrealistas, los trazos autógenos de los informalistas y las complejidades sin maniqueísmos que nos deporta el tratamiento de la artista como enferma mental, las figuras dibujándose a ellas mismas, sin referentes externos de las que ser signos posibles, pero, a la vez, tampoco disueltas en las complacencias ciegas de la abstracción plástica. Las figuras impensables, impuestas como presencias turbadoras, resistentes a la distancia contemplativa. Contra todo orden de consuelo, las imágenes figurales de Unica Zürn son grandes solitarias. 


\section{NOTAS}

1 Respecto a las exposiciones dedicadas a Unica Zürn desde su muerte en 1970, son estas: Ya entre diciembre de ese mismo año y las primeras semanas de 1971 se celebró en la parisina Galerie La Pochade una exposición de algunos de sus dibujos, pero habrá que esperar a 1983-1984 para que se inaugure Pour Unica Zürn en el Institut Goethe de París. En 1999, es el Museum Bochum de Berlín el que acoge una muestra de sus trabajos.

En 2005, Ubu Gallery, de New York, reúne unos ochenta dibujos suyos (Unica Zürn: Drawings from the 1960s). A esta exposición le han seguido, en esta misma galería, tres más: Unica Zürn: Twelve Painting+Two Drawings (noviembre 2010), otra dedicada a los dos: Bound: Hans Bellmer \& Unica Zürn, durante el mes de marzo de 2012, y la última en 20132014: Witnessing Visions: Brion Gysin, Henri Michaux, Judit Reigl, Unica Zürn.

En 2006-2007 pudo verse en París un conjunto de cien dibujos suyos en Halle Saint-Pierre, una sala dedicada al Art Brut y Outsider Art. En Herford (Alemania), Artaud, Michaux y Zürn fueron representados en Loss of Control: Crossing the Boundaries to Art from Felicien Rops to the Present. Y, en 2009, Unica Zürn: Dark Spring estuvo en The Drawing Centre (New York).

2 Me permito recomendar la consulta del espléndido catálogo de la exposición que pudo verse en 1993 en el Centro de Arte Reina Sofía: Visiones paralelas. Artistas modernos y arte marginal, editado por Maurice Tuchmann y Carol S. Eliel.

${ }^{3}$ Roger Cardinal, Roger, "Unica Zürn: desseins si denses". Unica Zürn (Paris : Éditions du Panama, 2006), 11.

4 Ibid., 14.

${ }^{5}$ Anouchka D'Anna, Unica Zürn. L'écriture du vertige (Paris: Éditions Cartouche, 2010), 43.

${ }^{6}$ Der Mann im Jasmin -escrito por su autora en alemán- aparece primero en Francia, en la prestigiosa Gallimard, en 1971 (L'Homme-Jasmin). En Alemania se publicará seis años después (en la editorial Verlag Ullstein). Dunkler Frühling es publicado en 1969 en alemán (ed. Merlin Verlag), y en 1970 en francés (Sombre printemps), en la edi- torial Pierre Belfond, con una traducción de Ruth Henry y Robert Valançay, muy poco antes de la muerte de Unica. En España, ya en 1986, Seix Barral, con traducción directa del alemán por Ana $\mathrm{M}^{\mathrm{a}}$ de la Fuente, reunió ambos textos en un volumen (Primavera sombría, El hombre jazmín). En 2004, Siruela reunió algunos de sus relatos con selección de Cecilia Dreymüller -y un breve prólogoy traducción de la misma De la Fuente: El trapecio del destino y otros cuentos. Algunos de ellos son verdaderamente deslumbrantes. También en Siruela apareció en 2005 Primavera sombría y en 2006 El hombre jazmín, ambos con la traducción que tuvieron en Seix Barral.

7 Acerca de la singularidad de los anagramas compuestos por Zürn, puede consultarse: Victoria Appelbe, "Du wirst dein Geheimnis sagen' ('Tu diras ton secret'). L'anagramme dans I'œuvre d'Unica Zürn". Unica Zürn (Paris: Éditions du Panama, 2006), 23-44.

8 Unica Zürn, "Rencontre avec Bellmer". Vacances à Maison Blanche. Derniers écrits et autres inédits (Paris: Gallimard, 2006), 35.

9 Ibid., 37. Se trata del rostro de Jean-Louis Barault, del film Les Enfants du paradis.

${ }^{10} \mathrm{ld}$.

${ }^{11}$ D'Anna, Unica Zürn. L'écriture du vertige, 32.

${ }^{12}$ D'Anna, Unica Zürn. L'écriture du vertige, 53.

${ }^{13}$ André Breton, "Manifeste du surréalisme" (1924). In Fuvres complètes, I, 311-346 (Paris: Gallimard, 1988), 328.

${ }^{14} \mathrm{Y}$ en un breve escrito que acompaña a la reedición en 1955 de los Manifiestos, Du surréalisme en ses œuvres vives, nos encontramos con estas líneas iniciales: "Es hoy notorio que el surrealismo, en tanto que movimiento organizado, ha tenido nacimiento mediante una operación de gran envergadura dirigida al lenguaje. A este respecto, nunca se repetiría demasiado que los productos del automatismo verbal o gráfico que han comenzado a aparecer no poseen en el espíritu de sus autores ningún criterio estético" (Breton, André. 2008. "Du surréalisme en ses œuvres vives". Écrits sur l'art et autres textes. Fuvres complètes, IV Paris : Gallimard, 2008, 19).
${ }^{15} \mathrm{lbid}$., 809-10.

${ }^{16}$ Con fecha de 27 de diciembre de 1957, se lee en "Notas de una anémica": "En cinco días, este año llega a su fin. Un año de grandes encuentros. He podido acompañar a Hans Bellmer a todas las sesiones de pose para sus retratos: Man Ray, Gaston Bachelard, Henri Michaux, Wifredo Lam, Hans Arp, Victor Brauner, Max Ernst" (Unica Zürn, "Notes d'une anémique (1957/1958)". In Vacances à Maison Blanche. Derniers écrits et autres inédits. Paris: Gallimard, 2006, 17).

${ }^{17}$ Michaux, Henri. 1972. Emergences-Résurgences. Genève-Paris: Albert Skira/Flammarion, p. 5.

$$
\begin{aligned}
& { }^{18} \text { lbid., p. } 7 . \\
& { }^{19} \text { lbid., } 35 .
\end{aligned}
$$

${ }^{20}$ Ruth Henry, "Rencontre avec Unica". En Zürn, Unica. Sombre printemps (Paris: Privat/Le Rocher, 2007), 97-8.

${ }^{21}$ André Breton, "L'Art des fous, la clé des champs" (1948). In Écrits sur I'art et autres textes. Fuvres complètes, IV, 730.

${ }^{22}$ Gaston Bachelard, Lautréamont (México: FCE, 1985), 46.

${ }^{23}$ Ibid., 66.

${ }^{24}$ No reprimo traer aquí la "precursora" definición que da Kant de la noción de idea estética: "Por idea estética entiendo aquella representación de la imaginación que ofrece ocasión para pensar mucho, sin que, sin embargo, pueda serle adecuada ningún pensamiento determinado, esto es, un concepto; que, en consecuencia, ni alcanza ni puede hacer plenamente comprensible ningún lenguaje" (Immanuel Kant, Crítica del discernimiento, Madrid: Antonio Machado Libros, 2003, 280-1).

${ }^{25}$ Gaston Bachelard, La poétique de la rêverie (Paris: PUF, 1984), 2.

${ }^{26}$ Gaston Bachelard, Fragments d'une poétique du Feu (Paris: PUF, 1988), 52.

${ }^{27}$ Gaston Bachelard, La poétique de l'espace (Paris: PUF, 1986), 10.

${ }^{28}$ Jean-François Lyotard, Discours, figure (Paris: Klinksieck, 1971), 211.

${ }^{29}$ Gilles Deleuze, Francis Bacon. Logique de la sensation (Paris: Éditions de La Différence, 1996), 9. 


\section{REFERENCIAS}

D'Anna, Anouchka. 2010. Unica Zürn. L'écriture du vertige. Paris: Éditions Cartouche.

Bachelard, Gaston. 1985. Lautréamont. Trad. de A. Marín del Campo. México: FCE.

Bachelard, Gaston. 1984. La poétique de la rêverie. Paris: PUF.

Bachelard, Gaston. 1988. Fragments d'une poétique du Feu. Paris: PUF.

Bachelard, Gaston. 1989. La poétique de l'espace. Paris: PUF.

Bellmer, Hans. 2009. Pour Unica Zürn : Lettres de Hans Bellmer à Henri Michaux. Paris: Éd. Ypsilon.

Bellmer, Hans, et Unica Zürn. 1994. Lettres au docteur Ferdière. Paris: Séguier.

Breton, André. 1988. CEuvres complètes, I. Paris: Gallimard.

Breton, André. 2008. Écrits sur l'art et autres textes. Fuvres complètes, IV. Paris: Gallimard.

Brousta, Jean. 1999. "Unica Zürn. Les Confidences de la folie." L'Information Psychiatrique 75 (1): 151-60.

Colvile, Georgiana M. M., et Katharine Conley. 1998. La Femme s'entête. La Part du féminin dans le surréalisme. Paris: Lachenal \& Ritter.

Delavenne, Patrice. 1986. "Unica Zürn ou la folie à livre ouvert." Frénésie 1: 57-73.

Deleuze, Gilles. 1996. Francis Bacon. Logique de la sensation. Paris: Éditions de La Différence.

Ferdière, Gaston. 1978. Les mauvaises fréquentations. Paris: Éd. Jean-Claude Simoën.

Henry, Ruth. 2007. "Rencontre avec Unica." In Zürn, Unica. Sombre printemps, 95-115. Paris: Privat/Le Rocher.

Hubert, Renee R. 1994. "Self-Recognition and Anatomical Junctures: Unica Zürn and Hans Bellmer." In Magnifying Mirrors: Women, Surrealism \& Partnership, 141-71. Lincoln: Nebraska UP.

Irigaray, Luce. 1985. "Une lacune natal: pour Unica Zürn." Le Nouveau Commerce 62-63: 39-47.
Kant, Immanuel. 2003. Crítica del discernimiento. Trad. de R. R. Aramayo y S. Mas. Madrid: Antonio Machado Libros.

Lyotard, Jean-François. 1971. Discours, figure. Paris: Klinksieck.

Michaux, Henri. 1972. Emergences-Résurgences. Genève-Paris: Albert Skira/Flammarion.

Plumer, Esra. 2016. Unica Zürn : Art, Writing and Postwar Surrealism. London/New York: I. B. Tauris, Limited.

Rabain, Jean-François. 1998. "Sublimation et identifications croisées : les "jeux à deux" de Hans Bellmer et d'Unica Zurn (sic)." Revue française de psychanalyse 4: 1247-64. https:// doi.org/10.3917/rfp.g1998.62n4.1247

Suleiman, Susan Rubin. 1998. "Dialogue and Double Allegiance: Some Contemporary Women Artists and the Historical Avant-garde." In Mirror Images: Women, Surrealism, and SelfRepresentation, edited by Whitney Chadwick, 128-54. Cambridge: MIT.

Zürn, Unica. 1967. Oracles et spectacles, Paris: Georges Visat.

Zürn, Unica. 1991. L'Homme-Jasmin, avec préface d'André Pieyre de Mandiargues. Paris : Gallimard.

Zürn, Unica. 2004. El trapecio del destino y otros cuentos. Trad. de A. $\mathrm{M}^{\mathrm{a}}$ de la Fuente. Madrid: Siruela.

Zürn, Unica. 2005. Primavera sombría. Trad. de A. $M^{a}$ de la Fuente. Madrid: Siruela.

Zürn, Unica. 2006. El hombre jazmín. Trad. de A. $\mathrm{M}^{\mathrm{a}}$ de la Fuente. Madrid: Siruela.

Zürn, Unica. 2006. Vacances à Maison Blanche. Derniers écrits et autres inédits. Trad. de R. Henry. Paris : Gallimard.

Zürn, Unica. 2007. Sombre printemps. Paris: Privat/Le Rocher.

V. AA. 2006. Unica Zürn. Paris : Éditions du Panama.

V. AA. 1977. "La femme surréaliste." Obliques 14-15.

VV. AA. 1981. "Approche d'Unica Zürn." Nouveau Commerce 49. 
